polyploidy, multiple allelomorphs, incompatibility genes, linkage, mating systems (especially those which lead to inbreeding), mutation, migration, selection and small populations. The treatment is essentially mathematical, so that anyone wishing to make use of the book must be prepared for some algebra. The algebra is not, however, over-formidable, and in many places explanatory notes are used to make clear points which, while doubtless familiar to mathematicians, may be new to geneticists. The difficulty which might arise from a mathematical treatment is also reduced by a commendable clarity of exposition of the points at issue. In this respect, the book is unusually good. Practical examples are worked out as illustrations of the method, and further examples are included as exercises at the ends of the chapters.

While the author does not confine his attention to American investigations of problems in population genetics, these do, in fact, occupy the major part of his account. The work of Wright, in particular, is presented at considerable length. The treatment of inbreeding, for example, is almost entirely based on Wright's method of path coefficients. The exposition of this method, it may be noted, is very clear and will add to the value which the book will hold for many readers.

To summarize, therefore, the book is limited in its scope to the formal genetical properties of populations. But, within this limitation, it is both comprehensive in its coverage and clear in its exposition. It should find a useful place in the teaching of advanced genetics. The production of the book is not up to the standards which we should expect of works published in occidental countries, but the language and style are such as might well be copied by many students to whom English is the native language. Dr. Li has set a commendable standard for genetical publications from China. It would indeed be encouraging to feel able to expect from that country further books of this standard.

K. MATHER

\section{DEVELOPMENT OF PLANT PHYSIOLOGY}

\section{Annual Review of Plant Physiology}

Daniel I. Arnon (Editor), and Leonard Machlis (Associate Editor). Vol. 1. Pp. $\mathrm{x}+364$. (Stanford, Calif.: Annual Reviews, Inc.; London: H. K. Lewis and Co., Ltd., 1950.) 6 dollars.

TCHE reviewers in Nature of Vols. $17^{1}$ and $18^{2}$ of the "Annual Review of Biochemistry" referred to the future appearance in 1950 of a new "Annual Review of Plant Physiology". We are sure that they will wish to join with us in congratulating the editors and the publishers of the new "Review", the first volume of which has recently been published.

In the preface, the editors announce, rather ambitiously, that they seek "to provide annually a critical evaluation of all branches of plant physiology", and to cover the subject completely "over a period of several" years. They are particularly anxious that the new publication should contribute towards the knitting of closer ties between physiologists active in agricultural specialities and those engaged in fundamental research. In the present volume, there are chapters on herbicides, growth-regulating substances in horticulture, post-harvest physiology of fruits, mineral nutrition, and soil moisture in relation to plant growth, in addition to discussions on carbon dioxide fixation, organic acid metabolism, the transformation of sugars and the respiration of higher plants. It is, in fact, evident that the new "Review", while pursuing the policy established by the parent publication, is fully conscious of its responsibility for maintaining a tradition established by such men as van Helmont, Mariotte and Stephen Hales. (The name of Pfeffer nestles unobtrusively in the long author index at the end of the volume.) How these older workers would have applauded the spirit of inquiry which prompts the observation on p. 274 : "Even if a causal relationship between respiration and water intake were proven, we should still wish to know how an increase in respiration can cause an increase in water intake". How they would have approved the advice offered on p. 289: "Each piece of work requires careful scrutiny of the data which are used to support the conclusions reached".

Most of the authors have succeeded admirably in providing "a critical assessment of the state of knowledge in their selected field". No doubt, readers will experience a feeling of gratitude to writers who, at the end of a 34-page article, in which Pauling's classical solutions of the structures of micas and Guggenheim's theory of gas adsorption are both under discussion, are moved to regret that they have not found space to mention many excellent papers, their intent being "to select papers to illustrate the prominent features of soil chemistry . . . subject to generalisation under the broad title of the paper".

There is, in addition to the lengthy author index, a subject index which is useful for ease of reference. The selection of topics for inclusion in this index seems sometimes to have been a little arbitrary. It is not clear, for example, why the inquirer interested in "sources of error in isotope tracer technique" should be referred merely to work with radioactive phosphorus.

Editorial policy appears not yet to have crystal. lized with regard to the arrangement of the literature lists at the end of each review. In ten of the fifteen lists, the bibliographical references are collected at the end of the chapter in the order in which they are cited in the text. In the remaining five lists, an alphabetical sequence has been followed, and in one instance the references are not numbered. It would appear that the "Annual Review of Biochemistry" is confronted with a similar dilemma, for its editors have asked readers to offer recommendations.

It is, perhaps, inevitable that, in a volume of $\mathbf{3 6 4}$ pages, a few errors should have escaped the diligence of the proof readers. Apart from trivial errors of spelling which will scarcely overtax the ingenuity of the informed reader, the generic name Hibiscus is spelt in a way which might surprise Virgil and Linnæus (p. 126). There is no real ambiguity in the use of the symbol $0^{-2}$ for the oxygen anion (p. 325) ; but it might have been helpful to distinguish on p. 55 between published and unpublished data.

It would be the height of folly, however, to attempt to judge the quality of fruit merely by inspection of the surface bloom. It would indeed be difficult to over-estimate the very great debt which we owe to the promoters of this new "Review". There is little doubt that the new series here inaugurated will prove indispensable to all those interested in the growth of plants.

J. P. RICHES

Nature, 163, 821 (1949)

Nature, 165, $740(1950)$. 